have yet witnessed. The sky was nearly unclouded, and the moon had not yet risen; a band of light forming an arc extended from west to east, under the Polar Star. It just touched, by its upper boundary, the stars $\gamma$ and $\beta$ of the Great Bear, and nearly touched by its lower fringe the star Cor Caroli ; this gives some idea of its breadth. Beams of light extended from the upper fringe towards the North Star, with greater or less intensity, fading away, however, very rapidly. Towards $9.30 \mathrm{p} . \mathrm{m}$. the eastern end of the arc became very luminous; immense beams spread up into the heavens, mostly parallel to the direction of the pointers. On the extreme east, a portion of the aurora presented that beautiful violet tint which is so relatively rare in these latitudes. Some of the beams towards the centre cf the arc also presented this colour, but only momentarily.

The arc, varying in intensity from moment to moment, rose towards the North Star, and became diffused, and towards 9 o'clock, the moon then appearing, nearly entirely disappeared; faint beams still, however, showing themselves from time to time. The summit of the arc was as nearly as possible under the North Star.

Royal College of Science for Ireland, Dublin, October 3

A BRIGHT aurora was seen here last evening (October 2). When first observed, at 7.0 p.m., the arc in the north-west was very distinct; at the same time two cloud-like patches of light were seen in the north-east at an elevation of about $30^{\circ}$. At 7 . Io the display reached its greatest brilliancy, narrow streamers extending upwards from the arc, as frequent intervals ; several pale flashes of light taking place over the arc. At this time the light patches had been replaced by others, and several new ones had appeared rapidly, the whole series forming a large arc springing from the east-north-east point, and extending towards the west-south-west, at 7.20 nearly forming a complete arch. By 7.30 the sky had become much overcast; still the strong glow continued in the north-west, while a lighting up of the clouds indicated the continued occurrence of the light patches. At 9.30 the sky was clear again, and every trace of aurora had vanished. The light of the aurora was quite colourless.

Kenley, Surrey, October 3

SYDNEY Evershed

LAST night, the 2nd inst., I here witnessed a very fine specimen of the Aurora Bonealis. It was in the form of radiating lines or ribs, having spaces between, equal to the $n$ idth of the ribs, namely, equal light and equal shadow; the whole springing from a centre about $15^{\circ}$ from the zenith in a south-westerly direction. When I first perceived the light, at 6.45 p.m., it was faint and of the colour of moonlight, and was not distinctly traceable all over, but by filling up the void, in the $\mathrm{n}$ ind's eye, the whole gave the appearance of an immense dome. Fifteen minutes later it had all disappeared, but at 7.15 it began to flash out in different places like slow lightning, principally at the zenith, much brighter than before, but still of the same colour, and around the centre the light took the shape of a sort of eccentric vortex ring.

University Club, Newcastle-on-Tyne, October 3

ABout a quarter to seven this evening I became aware that an aurora was in the sky. A clear, persistent light showed itself near the northern horizon, whilst in the eastern sky fluctuating luminous regions formed an arc between $7 \mathrm{~h}$, and $7 \mathrm{~h}, 15 \mathrm{~m}$. I noticed the position of that arc with respect to the constellations Aries and Pegasus. It began under $\alpha$ and $\beta$ Arietis, at about, say, $5^{\circ}$ north of the equator, and stretched parallel to a line through $\gamma$ and $a$ Pegasi, also at about $5^{\circ}$ north of the equator. At times the arc extended further towards the south-western horizon. At about $7 \mathrm{~h}$. 3om. a remnant of the arc shot a ray diagonally to the square formed by the four stars of Pegasus, i.e. from $\gamma$ to $\beta$ Pegasi. The colour of the aurora was pale white in the northern light; in the arc it was white, approaching slightly to a green approximate to that of the magnesium light.

22, Hadlow Road, Tunbridge (Kent), October 2

A RATHER uncommon display of aurora was seen here last evening, from about 7.15 to 7.40 p.m. Large patches of light, brilliantly white, were seen in the south and south-east, at a rough guess, extending from $10^{\circ}$ to $15^{\circ}$ in length and breadth, sonetimes shifting quickly from place to place, at other remaining stationary for a minute or two, but not attaining a greater average altitude than $30^{\circ}$ or $40^{\circ}$ from the horizon. They were slightly convex at the base, giving the appearance of a bank of clouds below. On looking to the north, a long, low arch of light was visible, with one or two long streamers, which rapidly disappeared, but the brilliancy was nothing compared with the patches before mentioned.

In connection with this display, perhaps it may be as well to mention that not only is there an enormous sun-spot passing over the sun's disc, but five other groups, one of which was nearly central yesterday, and showed signs of great disturbance in the course of a few hours.

Further Barton, Cirencester, October 3

\section{An Insect Attacking a Worm}

ON September 19, 1882, I was waiting for a train at Laqueville, in the Puy-de-Dome district of France, when I noticed a very large worm in the meadow, moving very rapidly from side to side. I touched it with my umbrella, expecting to see it retire into its hole, but, taking no notice of my touch, it continued its forward movement, and drew itself out of its hole with a jerk. I then saw that attached to the end of its tail was a caterpillarlike insect-no doubt the larva of some beetle-about $\mathrm{I}$ - inch long, the back covered with a series of shining black bands, ard the belly, which was furnished with a few short feet at the head and tail, was of dull greenish yellow. This insect, without relaxing its hold of the worm, which was moving along more rapidly than -I ever saw a worm move before, gradually shifted its bite along the belly of the worm till it had bitten about two inches, or rather less than one-third the whole length of the worm, which was more than six inches long. This it accomplished in about ten minutes, the bitten portion turning livid and swelling considerably, the worm's power of motion gradual'y ceasing. The insect then relaxed its hold, and crawled back along the back of the worm, and, seizing its tail, attempted to drag it backward, but finding the worm had still the power of slightly moving forward, it rapidly bit the belly of the worm where it had previously bitten it, and by this time the worm's power of forward motion had entirely ceased. The insect then appeared to survey the ground for some two feet behind the worm, and again seizin the tail, and fastening its own tail to a stalk of clover, it pulled strongly, not directly, but bending the worm sideways round a stalk of grass; gradually, very gradually, the swelled tail of the worm lengthened, and then I saw the whole body come back as it were a ring at a time, with a sort of resilient motion. The insect thus gained about one quarter of an inch, and in an hour and a half had drawn the worm in a sinuous line about 9 or Io inches. I was unable to observe longer, but I have no doubt the insect would eventually drag the worm back into the latter's own hole, where it had first attacked it.

No doubt such an incident is extremely common in France, where there are few birds, but I fancy the numerous birds in England may have nearly extirpated such an enemy of worms, which would form with the dead worm a somewhat conspicuons object for two or three hours.

EDWIN LAWRENCE

\section{White Ants}

HAving observed in NATURE (vol. xxvi. p. 343) some re. marks regarding White-ants' nests, it has occurred to me to put on record the following fact, which came under my observation.

A lady residing in Madras had a set of plain table glass ware in a cupboard, which had not been opened for some time. On looking into it one day, she found the glass more or less covered with the mud indicative of the presence of white-ants. The glass articles were at once removed and washed, but wherever the mud had been applied by the insects, it was found that the glass had a frosted appearance, which no amount of scrubbing would remove. Some of the articles were then sent to me for inspection, and I found that the lustrous surface of the glass had been completely destroyed, as if by some powerful corrosive, wherever the ant-mud had been in contact with it.

We know well enough the substances used for etching on glass, but I shall feel obliged if any of your correspondexits will explain how these insects managed to act on it in the destructive manner specified.

Museum, Madras, September 3 